Research Paper

\title{
Viola Yedoensis Suppresses Cell Invasion by Targeting the Protease and NF-KB Activities in A549 and Lewis Lung Carcinoma Cells
}

\author{
She-Fang Huang ${ }^{1}$, Shu-Chen Chu ${ }^{4}$, Yi-Hsien Hsieh², Pei-Ni Chen ${ }^{2,3}{ }^{凶}$, Yih-Shou Hsieh ${ }^{2,3} \bowtie$ \\ 1. Division of Chest Medicine, Department of Internal Medicine, Kaohsiung Armed Forces General Hospital, Kaohsiung City, Taiwan, ROC \\ 2. Institute of Biochemistry, Microbiology and Immunology, Chung Shang Medical University, Taichung City, Taiwan. \\ 3. Clinical Laboratory, Chung Shan Medical University Hospital, Taichung, Taiwan \\ 4. Institute and Department of Food Science, Central Taiwan University of Science and Technology, Taichung, Taiwan.
}

$\square$ Corresponding authors: Yih-Shou Hsieh, Ph.D., Institute of Biochemistry, Microbiology and immunology, Chung Shan Medical University, No 110, Section 1, Chien Kuo N. Road, Taichung 402, Taiwan, Tel.: +886-4-2473-0022 ext 11678, E-mail: csmcysh@csmu.edu.tw and Pei-Ni Chen, Ph.D., Institute of Biochemistry, Microbiology and immunology, Chung Shan Medical University, No 110, Section 1, Chien Kuo N. Road, Taichung 402, Taiwan, Tel.: +886-4-2473-0022 ext 12132, E-mail: peini@csmu.edu.tw

(c) Ivyspring International Publisher. This is an open access article distributed under the terms of the Creative Commons Attribution (CC BY-NC) license (https:// creativecommons.org/licenses/by-nc/4.0/). See http://ivyspring.com/terms for full terms and conditions.

Received: 2017.09.12; Accepted: 2017.12.21; Published: 2018.01.18

\begin{abstract}
Cancer metastasis is a vital trait in malignancies with complicated early diagnosis and therapeutic management. Therefore, the development of new remedies and the utilization of natural medicines that target metastasis are of great interest and have been studied extensively. Chinese medicinal herbs have various anti-carcinogenesis properties; however, the in vitro effect and mechanism of Viola yedoensis on cancer cell metastasis remains poorly understood. V. yedoensis extracts (VYE) can suppress the invasion of a highly metastatic human lung cancer cell line, A549 cells. According to gelatin zymography and casein zymography assays, VYE inhibited the activities of matrix metalloproteinases (MMPs) and urokinase-type plasminogen activator (u-PA). The results of reverse transcription-polymerase chain reaction and Western blotting revealed that VYE can alter the expression of proteinase inhibitor. VYE also suppressed the DNA binding activity of nuclear factor-kappa B. We concluded that VYE may inhibit tumor invasion by suppressing the activities of MMP and u-PA in lung cancer cells.
\end{abstract}

Key words: lung cancer, invasion, matrix metalloproteinase, urokinase-type plasminogen activator

\section{Introduction}

Metastasis is the main cause of death in patients with lung cancer. Metastasis is a complex process that involves the damage of the extracellular matrix (ECM) components, increase in cancer cell invasion from the primary tumor site, suspension in the circulatory system, and growth at a target organ [1, 2]. Various treatments in cancer research have targeted the prevention of metastasis. Every step in the metastatic cascade must be achieved for the successful manifestation of this phenomenon. Therefore, the blockade of any single step in the metastatic process would hinder metastasis. Matrix metalloproteinases (MMPs) and serine proteinase play a key role in cancer metastasis [3], particularly in damaging the
ECM. MMP-9 (gelatinase B, $92 \mathrm{kDa}$ ) and MMP-2 (gelatinase $\mathrm{A}, 72 \mathrm{kDa}$ ) are members of a unique family of zinc-dependent endopeptidases that regulate the key signaling pathways in cell growth, inflammation, migration, invasiveness, angiogenesis, and metastasis [4]. Urokinase-type plasminogen activator (u-PA), a type serine proteinase, is also involved in cancer metastasis and angiogenesis $[4,5]$.

Lung carcinoma, which develops from epithelial cells, is the most commonly diagnosed malignancy and the main cause of cancer-related deaths in Asian and Western countries with only approximately $15 \%$ chance of a 5-year survival rate [6]. Non-small cell lung cancer (NSCLC) is the most common type of 
lung cancer. NSCLC comprises $85 \%$ of lung cancers and is divided into subtypes, such as adenocarcinoma, squamous cell carcinoma, and large cell carcinoma. Cancer metastasis and drug resistance are two principal causes for the poor survival and prognosis of patients with lung cancer [7]. Therefore, inhibition of metastasis is one of the most important issues in cancer research.

Chemoprevention using non-toxic botanicals could be one of the strategies for cancer management by preventing, delaying, reversing, or suppressing carcinogenesis [8, 9]. Viola yedoensis is a popular medicinal herb with medical properties, such as anticoagulant [10], anti-inflammatory [11], and anti-bacterial [12] activities. Earlier reports have indicated that $V$. yedoensis contains flavone (including mono-C-hexoside, 6,8-di-C-hexosides, 6,8-di-C-pentosides, 6,8-C-hexosyl-C-pentosides, C-glycosides, and O-glycosides), dicoumarin (including dimeresculetin, euphorbetin, and esculetin) and cyclotides $[10,13,14]$. $V$. yedoensis inhibits $\beta$-hexosaminidase and histamine release and down-regulates the expression of inflammatory cytokines (such as IL-1 $\beta$, TNF- $\alpha$, IL-6, and iNOS) to block the inflammatory development in RBL-2H3 mast cells [15]. Nevertheless, the anti-cancer effect of $V$. yedoensis in human lung adenocarcinoma has not been investigated. In this study, we proposed that $V$. yedoensis may affect lung adenocarcinoma cells by exerting anti-cancer effects in vitro. This hypothesis is formulated on the basis that tumor metastasis is accompanied by the change in cell-matrix adhesion ability, the up-regulated degradation of ECM, and the increase in cell invasion and migration. The present study aimed to characterize the inhibitory effects and underlying mechanisms of $V$. yedoensis on the cell migration, invasion, and expression of the proteinase of lung adenocarcinoma cancer cells.

\section{Materials and methods}

\section{Preparation of VYE}

$V$. yedoensis was purchased from a store in Taichung, Taiwan, and VYE was prepared as previously described [16]. Air-dried whole plant (100 g) was boiled at $70{ }^{\circ} \mathrm{C}$ for $24 \mathrm{~h}$ with $500 \mathrm{~mL}$ of $50 \%$ ethanol. The solvent was removed, and the filtrate was lyophilized and stored at $-20{ }^{\circ} \mathrm{C}$. The recovery ratio of VYE is $17.68 \%$. Furthermore, the chemical profile of VYE was analyzed by using high-pressure liquid chromatograms (HPLC)-mass spectrometer. Briefly, VYE was analyzed by HPLC-mass spectrometer using a HPLC (Hitachi L-6200 with an L-4500 Diode Array detector) with a PE Sciex Qstar Pulsar ESI-TOF mass spectrometer. Samples $(10 \mu \mathrm{l})$ were injected into a Merck LiChrospher 100 RP-18 column $(4 \mathrm{~mm} \times 250 \mathrm{~mm})$. The column was equilibrated in $0.05 \%$ acetic acid/water (solution A), and elution of the components was performed by increasing the concentration of acetonitrile (solution B) from $0 \%$ to $60 \%$ in $30 \mathrm{~min}$ at a flow rate of 1 $\mathrm{ml} / \mathrm{min}$. Absorbance was monitored at $254 \mathrm{~nm}$.

\section{Cell culture}

A549 (human lung adenocarcinoma cell line), Lewis lung carcinoma (LLC, a mouse lung cancer cell line), and MRC-5 (normal human fetal lung fibroblast) cell lines were obtained from American Type Culture Collection (Manassas, VA) and cultured in either Dulbecco's Modified Eagle's medium (DMEM; for A549 and LLC) or Basal Medium Eagle (BME; for MRC-5) supplemented with $10 \%$ fetal bovine serum (FBS), $2 \mathrm{mM}$ glutamine, $100 \mathrm{U} / \mathrm{mL}$ penicillin, and 100 $\mu \mathrm{g} / \mathrm{mL}$ streptomycin. All cell cultures were maintained at $37^{\circ} \mathrm{C}$ in a humidified atmosphere of $5 \%$ $\mathrm{CO}_{2}$.

\section{Microculture tetrazolium (MTT) assay}

The cells were seeded onto 24-well plates at a density of $3 \times 10^{4}$ cells/well and were treated with VYE at a concentration of $0-100 \mu \mathrm{g} / \mathrm{mL}$ at $37^{\circ} \mathrm{C}$ for 24 h. After the exposure period, the media were removed, and the cells were washed with phosphate-buffered saline, followed by incubation with $0.5 \mathrm{mg} / \mathrm{mL}$ MTT in culture medium for an additional $4 \mathrm{~h}$. The blue formazan crystals of viable cells were dissolved and measured spectrophotometrically at $570 \mathrm{~nm}$ [17].

\section{Boyden chamber cell invasion and motility assays}

After pre-treatment with VYE for $24 \mathrm{~h}$, the cells were harvested, seeded to the Boyden chamber (Neuro Probe, Cabin John, MD) at $1.5 \times 10^{4}$ cells/well in serum-free medium, and incubated for another $24 \mathrm{~h}$ at $37^{\circ} \mathrm{C}$. For the invasion assay, $10 \mu \mathrm{L}$ of Matrigel $(0.5$ $\mathrm{mg} / \mathrm{mL}$ ) was applied to polycarbonate membrane filters $(8 \mu \mathrm{m}$ pore size). The bottom chamber of the apparatus contained standard medium (10\% FBS DMEM medium). The invaded cells were fixed with methanol and stained with Giemsa. Cell numbers were counted using a light microscope, whereas motility assay was performed as described for the invasion assay without the Matrigel coating [2].

\section{Determination of MMPs and u-PA by zymography}

The cells were treated with VYE $(0,10,25,50,75$, and $100 \mu \mathrm{g} / \mathrm{mL}$ ) for $24 \mathrm{~h}$. The samples were prepared with sodium dodecyl sulphate (SDS) sample buffer without boiling or reduction and were subjected to 
gelatin zymography and casein zymography analyses to determine the MMPs and u-PA activities, respectively. For gelatin zymography, the collected media were subjected to $0.1 \%$ gelatin- $8 \%$ SDS polyacrylamide gel electrophoresis (PAGE) to determine the MMP-2 and MMP-9. The gels were washed with $2.5 \%$ Triton X-100 after electrophoresis and then incubated in the reaction buffer. The gel was stained with Coomassie brilliant blue R-250, and u-PA activity was visualized by casein zymography [18-22]. In brief, $2 \% w / v$ casein and $20 \mu \mathrm{g} / \mathrm{mL}$ plasminogen were added to the $8 \%$ SDS-PAGE gels. The u-PA activity of the cells treated or untreated with VYE was measured as described in the gelatin zymography.

\section{Measurement of MMP-2 and u-PA promoter activity}

A $460 \mathrm{bp}(-218$ to +243$)$ segment from the 5 '-promoter region of the MMP-2 gene and a $644 \mathrm{bp}$ $(-562$ to +83$)$ segment from the $5^{\prime}$-promoter region of the u-PA gene were cloned. The pGL3-MMP-2 and pGL3-u-PA plasmids were transfected into SiHa cells using PolyJet ${ }^{\mathrm{TM}}$ reagent (SignaGen Laboratories, Gaithersburg, MD) according to the manufacturer's instructions. After incubation with berberine, cells were collected and disrupted by Luciferase Assay System (Promega, San Diego, CA). Firefly luciferase activities were standardized for $\beta$-galactosidase activity [23].

\section{Western blot analysis}

After treatment with different concentrations of VYE for $24 \mathrm{~h}$, the treated cells were lysed using a cold mammalian protein extraction buffer kit (GE Healthcare Bio-Sciences Corp., Piscataway, NJ) with protease inhibitor cocktails for $20 \mathrm{~min}$ to prepare the total cell lysates. Nuclear extracts were isolated by NE-PER Nuclear and Cytoplasmic Extraction Kit for Cultured Cells (Thermo Scientific, IL, USA) according to the manufacturer's instructions. Samples cell lysates were incubated with the TIMP-2, TIMP-1, PAI-1, NF- $\kappa$ B, p-p38, p38, p-Akt, p-ERK1/2 and ERK1/2 antibodies (Cell Singling Technology, Inc., Danvers, MA, USA), washed, and monitored by immunoblotting assays using specific secondary antibodies. For Figure 5D, member was immunoblotted with the appropriate antibodies, as described in the figure legends; the members were stripped with T-Pro stripping reagent (Southern Biotechnology Associates, Inc.,Birmingham, AL) and reprobed with indicated antibodies. The relative photographic densities were quantified by scanning the photographic negatives using a gel documentation and analysis system (Alpha-Imager 2000, Alpha Innotech Corporation, San Leandro, CA,
USA). After measuring the intensity of each band by densitometry, the relative intensities were calculated by normalizing the level to $\beta$-actin or C23 (Santa Cruz, CA, USA) from the corresponding sample [24].

\section{Electrophoretic mobility shift assay (EMSA)}

The binding of nuclear factor-kappa B (NF- $\kappa$ B) and activator protein-1 (AP-1) in nuclear extracts was assessed by EMSA with biotin-labeled double-stranded NF-кB (5'- AGTTGAGGGGACTTTCCCAGGC-3') and AP-1 (5'- CGCTTGATGAGTCAGCCGGAA-3') oligonucleotides. EMSA was conducted with Lightshift kit. Specific binding was confirmed with a 200 -fold excess of unlabeled probe as specific competitor. Gel shifts were visualized with a streptavidin-horseradish peroxidase, followed by chemiluminescence detection [25].

\section{Reverse Transcription-Polymerase Chain Reaction}

For reverse transcription, $2 \mu \mathrm{g}$ of total RNA was used as the template in a $20 \mu \mathrm{l}$ reaction with $4 \mu \mathrm{l}$ of dNTPs $(2.5 \mathrm{mM}), 2.5 \mu \mathrm{l}$ of Oligo dT $(10 \mathrm{pmole} / \mu \mathrm{L})$, and $200 \mathrm{U}$ of RTase. The appropriate primers 5'-GGCCCTGTCACTCCTGAGAT-3' and 5'-GGCATC CAGGTTATCGGGGA-3' for MMP-2 (473bp), 5'-TTG CGGCCATCTACAGGAG-3' and 5'-ACTGGGGATC GTTATACATC-3' for u-PA (351bp), 5'-GGATCCAGC CACTGGAAAGGCAACATG-3' and 5'-GGATCCGT GCCGGACCACAAAGAGGAA-3 for PAI-1 (254bp), 5'-GGCGTTTTGCAATGCAGATGTAG-3' and 5'-CA CAGGAGCCGTCACTTCTCTTG-3' for TIMP-2 (496 bp), and 5'-CGGAGTCAACGGATTTGGTCGTAT-3' and 5'-AGCCTTCTCCATGGTTGGTGAAGAC-3' for GAPDH (305bp) were used for PCR amplifications. PCR was performed using Platinum Taq polymerase (Invitrogen) as follows: 25 cycles at $94^{\circ} \mathrm{C}$ for $1 \mathrm{~min}, 55$ ${ }^{\circ} \mathrm{C}$ (u-PA and PAI-1) or $63{ }^{\circ} \mathrm{C}$ [MMP-2, tissue inhibitors of metalloproteinases (TIMP)-2, and glyceraldehyde-3-phosphate dehydrogenase (GAPDH)] for $1 \mathrm{~min}$, and $72{ }^{\circ} \mathrm{C}$ for $12 \mathrm{~min}$ [26].

\section{Statistical analysis}

Statistical significances were analyzed by one-way ANOVA with post hoc Dunnett's test. P value $<0.05$ was considered statistically significant (Sigma-Stat 2.0, Jandel Scientific, San Rafael, CA).

\section{Results}

\section{VYE has cytotoxic effect on LLC cells}

In the presence of $10,25,50,75$, and $100 \mu \mathrm{g} / \mathrm{mL}$ VYE concentrations, the viability of A549 cells was not significantly different from that of the control $(0$ $\mu \mathrm{g} / \mathrm{mL}$ ) after 24 treatments (Figure $1 \mathrm{~A}$ ), whereas that of LLC cells was reduced (Figure 1B). Following the 
same procedures, we found that this compound did not exert any significant cytotoxicity on non-malignant human fetal lung fibroblast MRC-5 (Figure 1C).

A

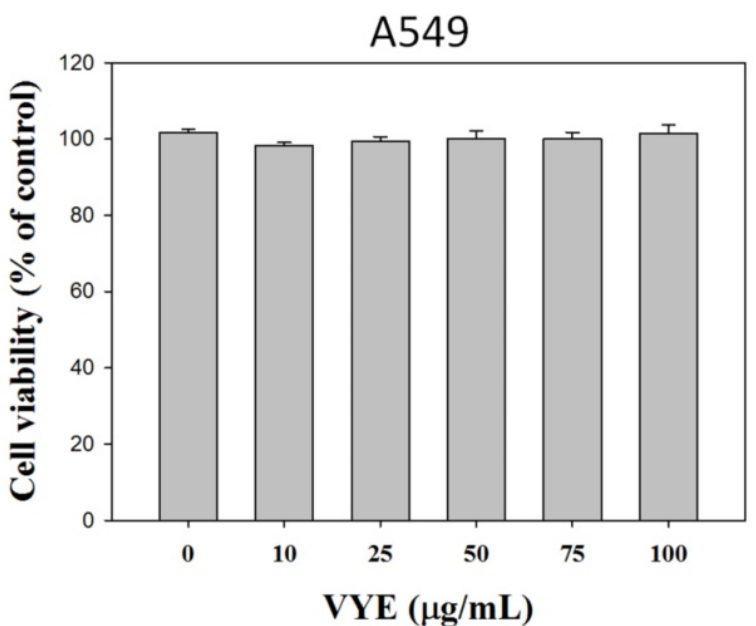

B

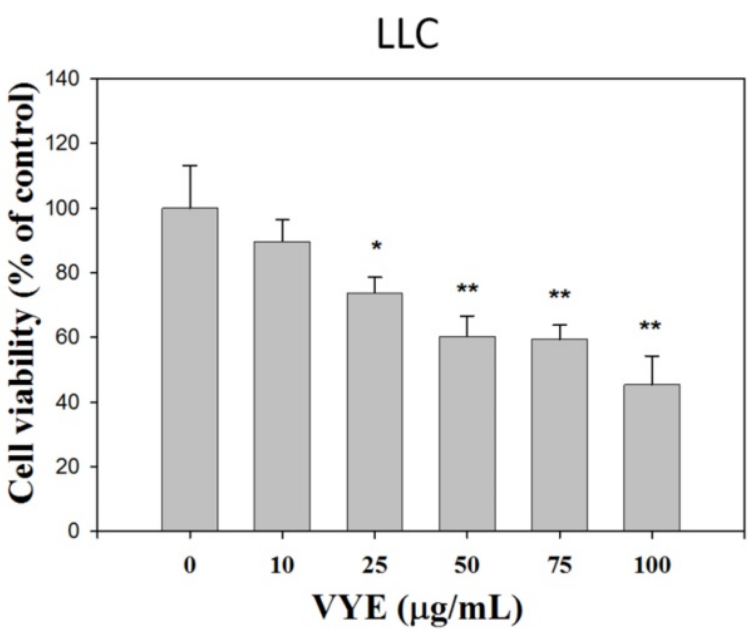

C

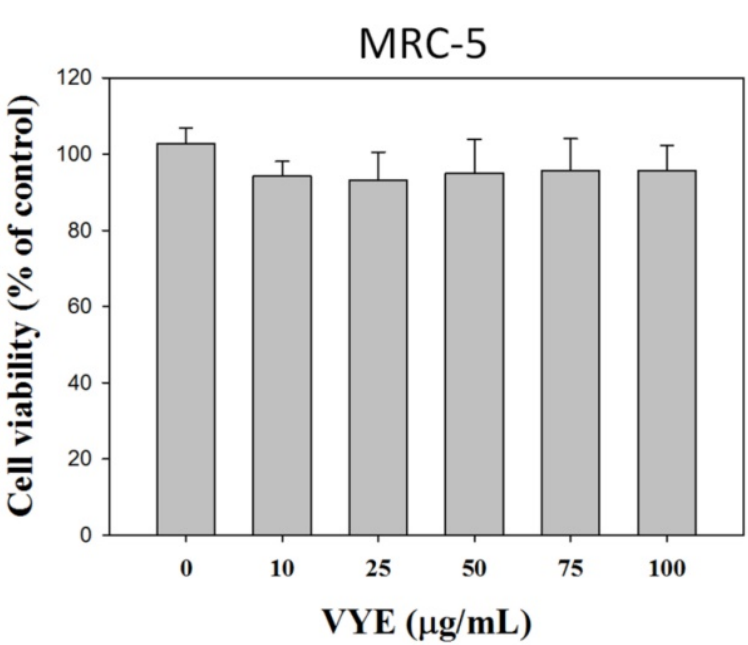

Figure 1. Effects of VYE on cell viability in lung cancer A549 and LLC cells. (A) A549 (B) LLC and (C) MRC-5 cells were treated with different concentrations of VYE for $24 \mathrm{~h}$ prior to MTT assay for cell viability. Results were statistically evaluated using one-way ANOVA with post hoc Dunnett's test $(* P<0.05 ; * * P<0.01)$. Results from three repeated and separate experiments were similar.
VYE inhibits the invasiveness and migration of A549 and LLC cells

The suppressive effects of VYE on the cellular migration potential and invasive activity of lung adenocarcinoma, A549 and LLC cells were also determined by conducting Boyden chamber invasion and migration assays. Quantitative analysis indicated that the invasiveness of A549 (Figure 2A) and LLC (Figure 2B) cells was reduced by $66.6 \%(P<0.001)$ and $82.2 \%(P<0.001)$, respectively, when treated with 100 $\mu \mathrm{g} / \mathrm{mL}$ of VYE. VYE also significantly reduced the migration $(P<0.001)$ of A549 (Figure 2A) and LLC (Figure 2B) cells in a concentration-dependent manner. Therefore, VYE could reduce the metastatic activity of A549 and LLC cells.

\section{VYE suppresses MMP and u-PA of A549 and LLC cells}

Given that the expression and activity of u-PA and MMPs are critical to cell invasion, the expression and activity of u-PA and MMPs of A549 and LLC cells treated with different concentrations of VYE were examined by casein zymography and gelatin zymography, respectively. VYE reduced the activities of both MMP-2 $(P<0.001)$ (Figure 3A) and MMP-9 $(P<0.001)$ (Figure 3B) of A549 and LLC cells by $96.6 \%$ and $99.4 \%$ that were treated with $100 \mu \mathrm{M}$ of VYE in gelatin zymography, respectively. In addition to MMPs, quantification analysis indicated that the activities of the upper stream u-PA in A549 and LLC cells were reduced by $33.7 \%(P<0.01)$ and $99.1 \%$ $(P<0.001)$ when cells were treated with 100 $\mu \mathrm{g} / \mathrm{mL}$ of VIE, respectively (Figures $3 \mathrm{~A}$ and $3 \mathrm{~B}$ ). To evaluate the effects of VYE on the MMP-2 and u-PA promoter, we performed a transient transfection with the pGL3-MMP-2 and pGL3-u-PA promoter in A549 cells. The luciferase activities of the transfectants of MMP-2 and u-PA promoter treated with VYE were significantly reduced in A549 cells (Figure 3C)

\section{Effects of VYE on TIMP-1, TIMP-2, and PAI-1 protein expression}

The physiological activities of MMP-2 and MMP-9 are closely related to those of the specific endogenous inhibitors, TIMP-2 and TIMP-1, respectively. Plasminogen activator inhibitor-1 (PAI-1) is the specific endogenous inhibitor for u-PA. Therefore, Western blot was performed to determine the effects of VYE on TIMP-2, TIMP-1, and PAI-1 expression levels. The results showed that TIMP-2 and TIMP-1 protein levels were gradually decreased with the concentration of VYE in A549 (Figure 4A) and LLC (Figure 4B) cells, respectively. PAI-1 protein expression levels were gradually increased in A549 
cells (Figure 4A) but gradually decreased in LLC cells with the increasing concentration of VYE (Figure 4B).

A
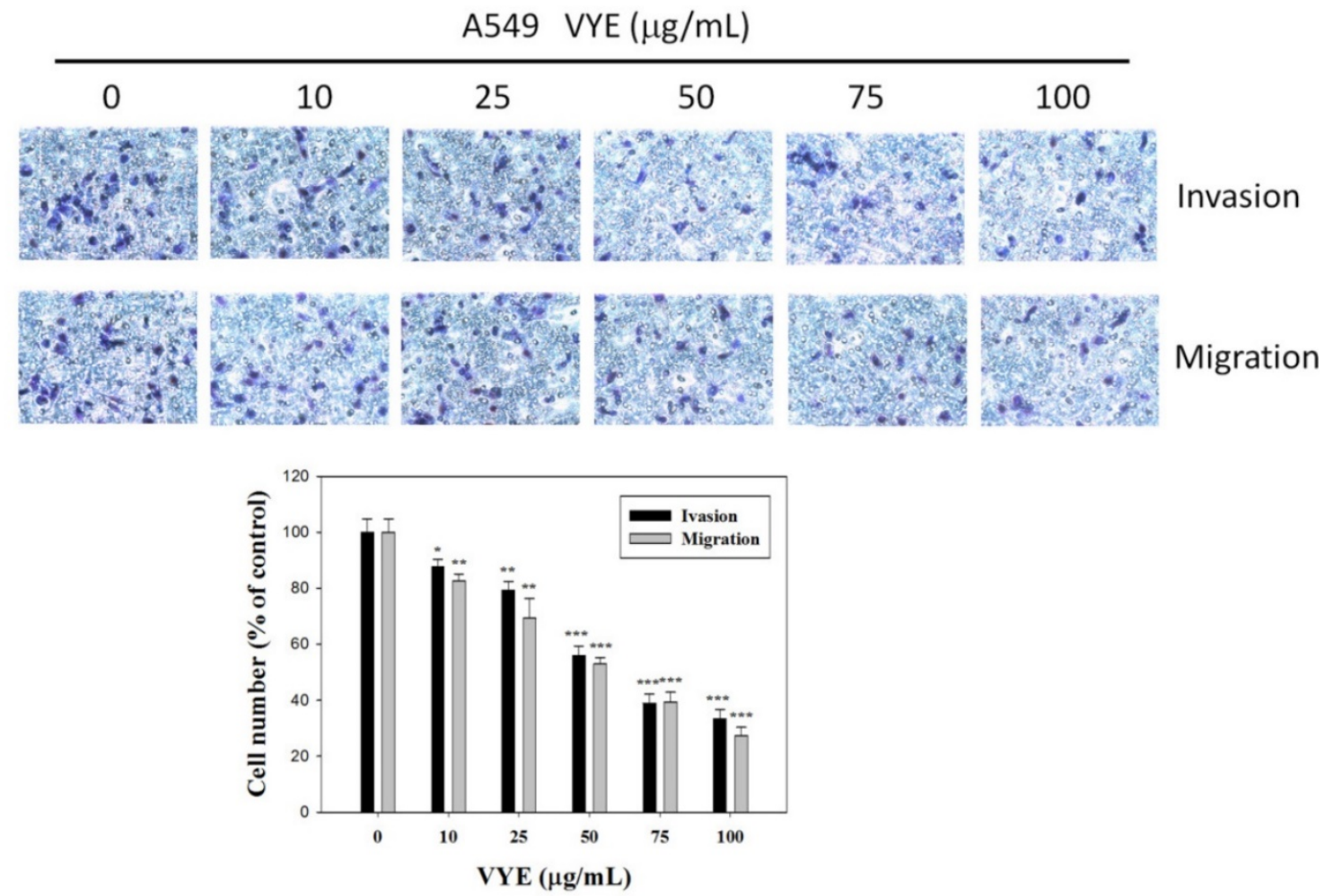

B

$\operatorname{LLC} \operatorname{VYE}(\mu \mathrm{g} / \mathrm{mL})$
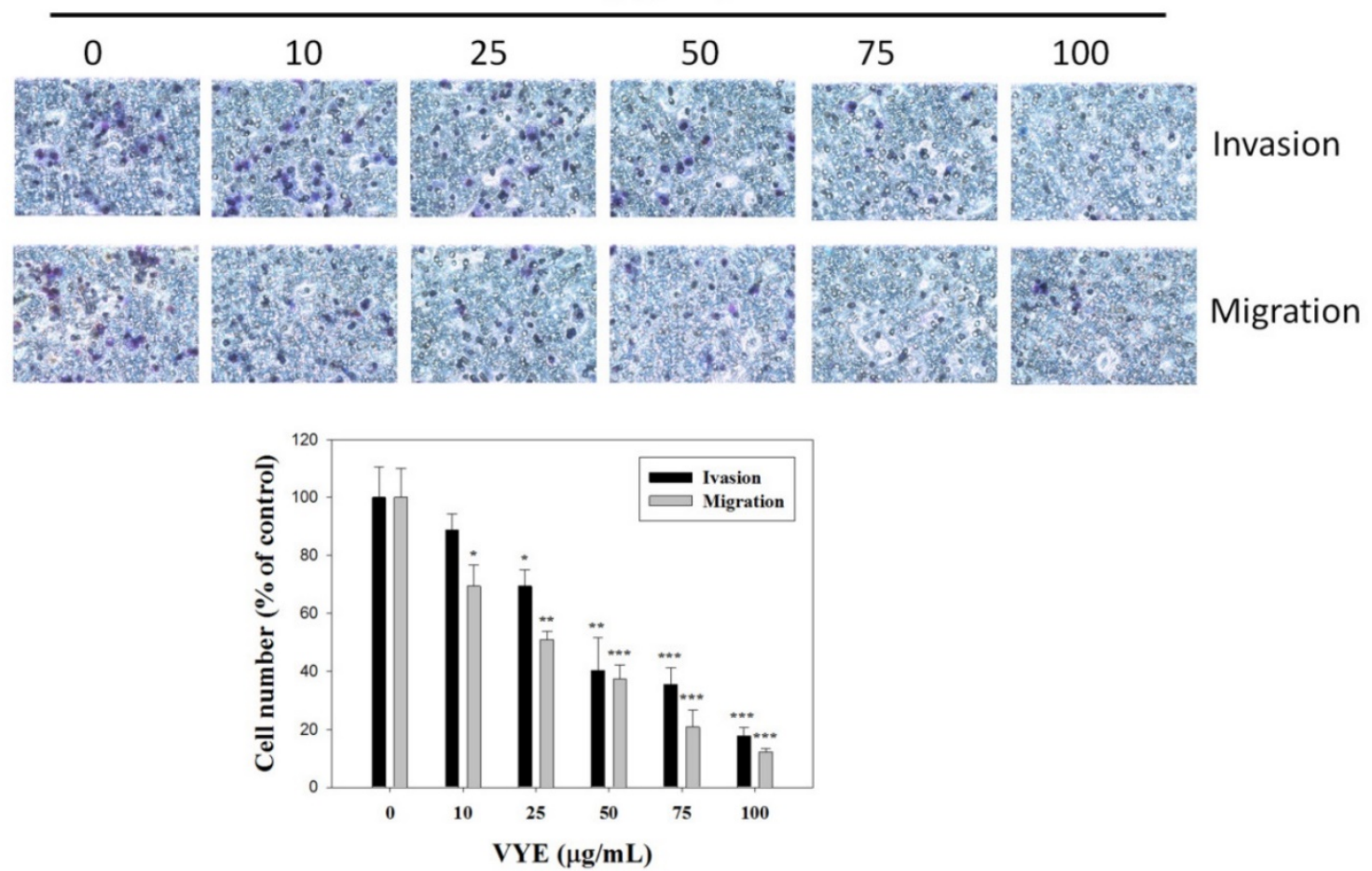

Figure 2. Effects of VYE on the cell migration and invasion assays in lung cancer A549 and LLC cells. Cell invasion and migration assays in (A) A549 cells and (B) LLC cells were measured after the cells were treated with different concentrations (i.e., $0,10,25,50,75$, and $100 \mu \mathrm{g} / \mathrm{mL}$ ) of VYE for $24 \mathrm{~h}$. Data represent mean \pm SD, and those of the control were assumed as $100 \%$. Statistical significance of the results was analyzed using one-way ANOVA with post hoc Dunnett's test $(* P<0.05 ; * * P<0.01 ; * * * P<0.001)$. 
A

\section{A549}

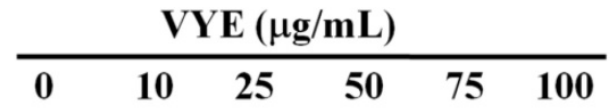

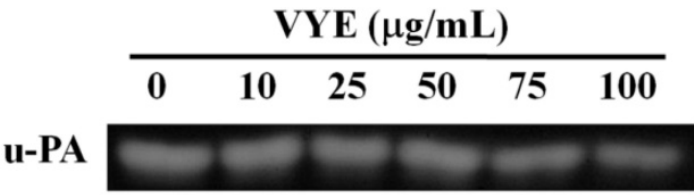

MMP-2
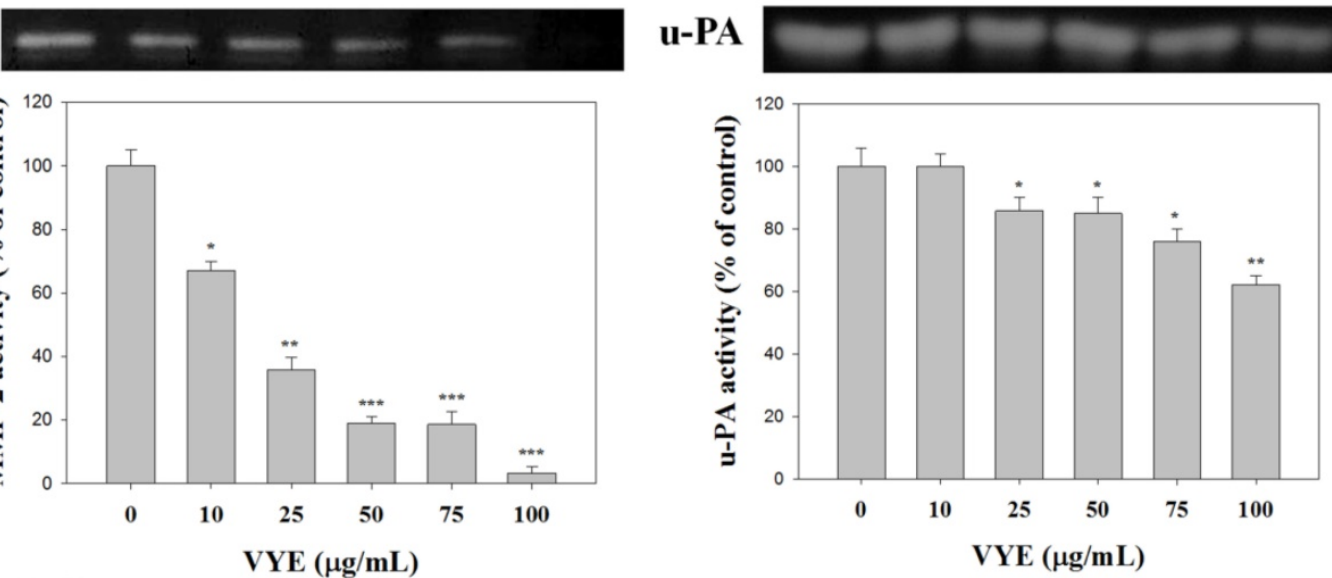

B

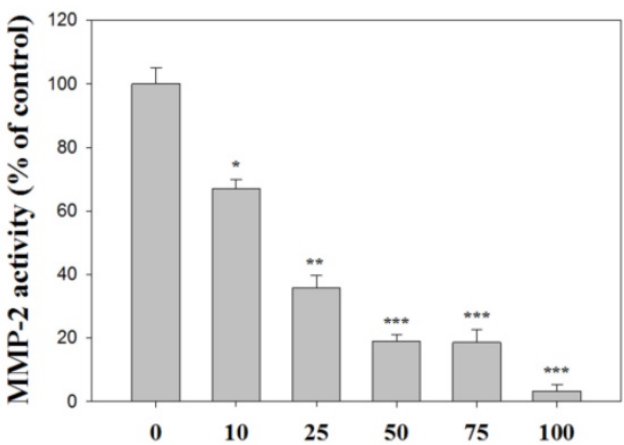

\section{LLC}

VYE $(\mu \mathrm{g} / \mathrm{mL})$

VYE $(\mu \mathrm{g} / \mathrm{mL})$

\section{VYE $(\mu \mathrm{g} / \mathbf{m L})$}

\begin{tabular}{llllll}
\hline 0 & 10 & 25 & 50 & 75 & 100
\end{tabular}

MMP-9
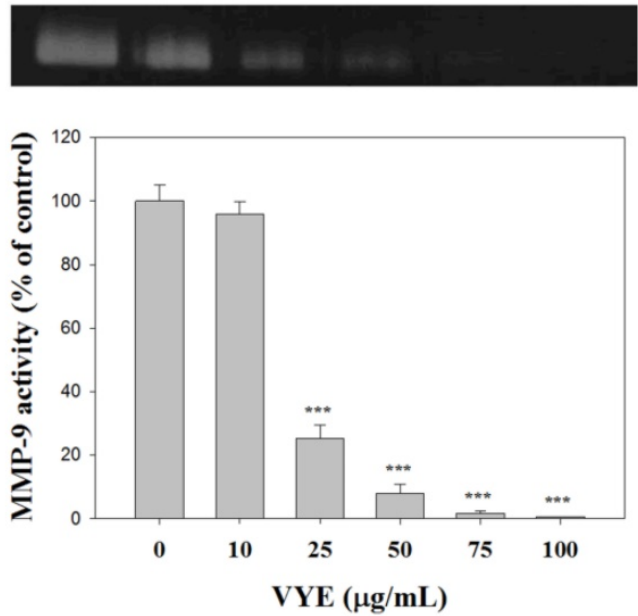

C

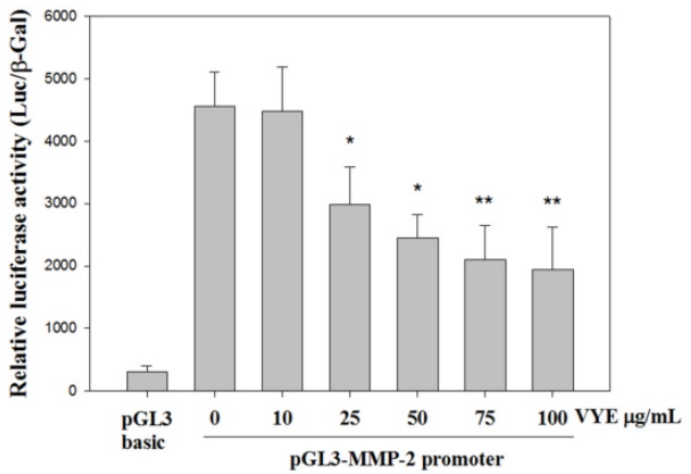

VYE $(\mu \mathbf{g} / \mathbf{m L})$
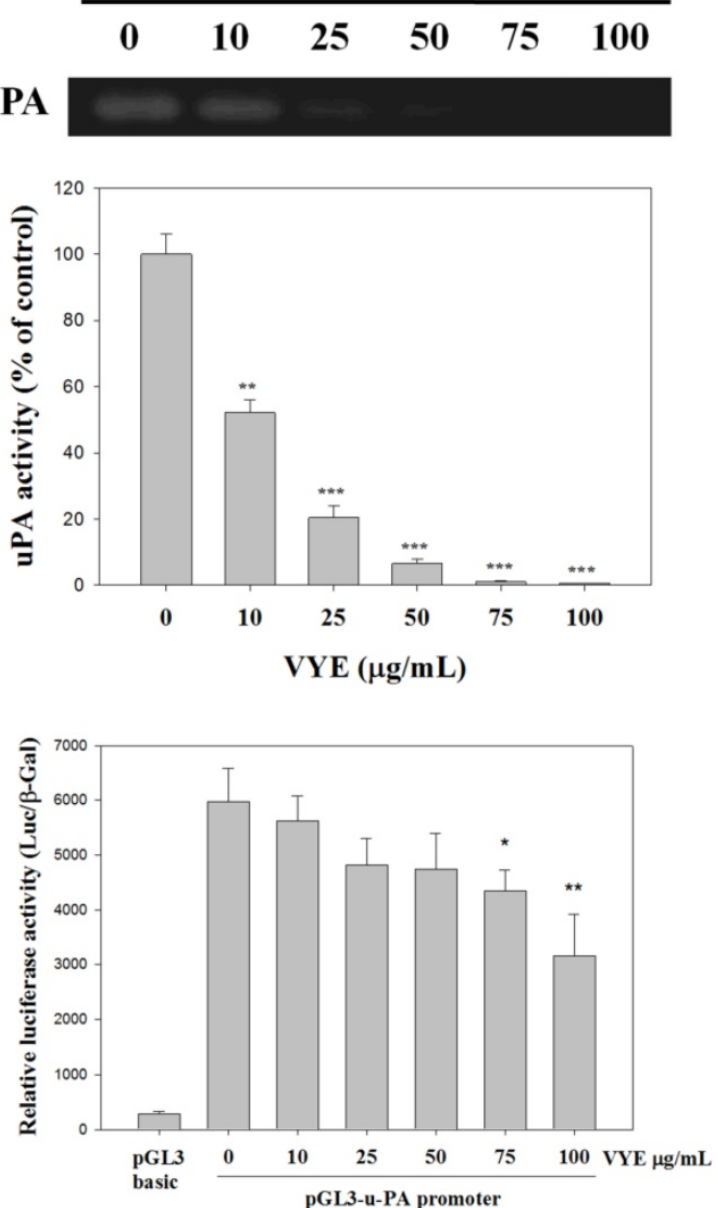

Figure 3. Effects of VYE on MMPs and u-PA in lung cancer A549 and LLC cells. MMP-2 and MMP-9 activities were measured by gelatin zymography after (A) A549 and (B) LLC cells were treated with different concentrations (i.e., 0, 10, 25, 50, 75, and $100 \mu \mathrm{g} / \mathrm{mL}$ ) of VYE for $24 \mathrm{~h}$. (A) A549 and (B) LLC cells were treated with VYE for $24 \mathrm{~h}$ and then subjected to casein zymography to analyze the activities of u-PA. (C) Luciferase activity was measured in transiently transfected A549 cells using PGL3-MMP-2 and pGL3-u-PA. Data represented mean \pm SD, and those of the control were assumed as $100 \%$. Statistical significance of results was analyzed using one-way ANOVA with post hoc Dunnett's test $(* P<0.05$; $* * P<0.01$; $* * * P<0.001)$. 
A

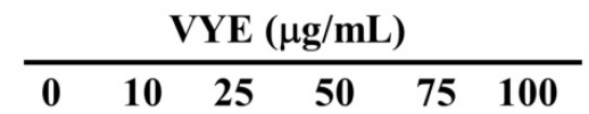
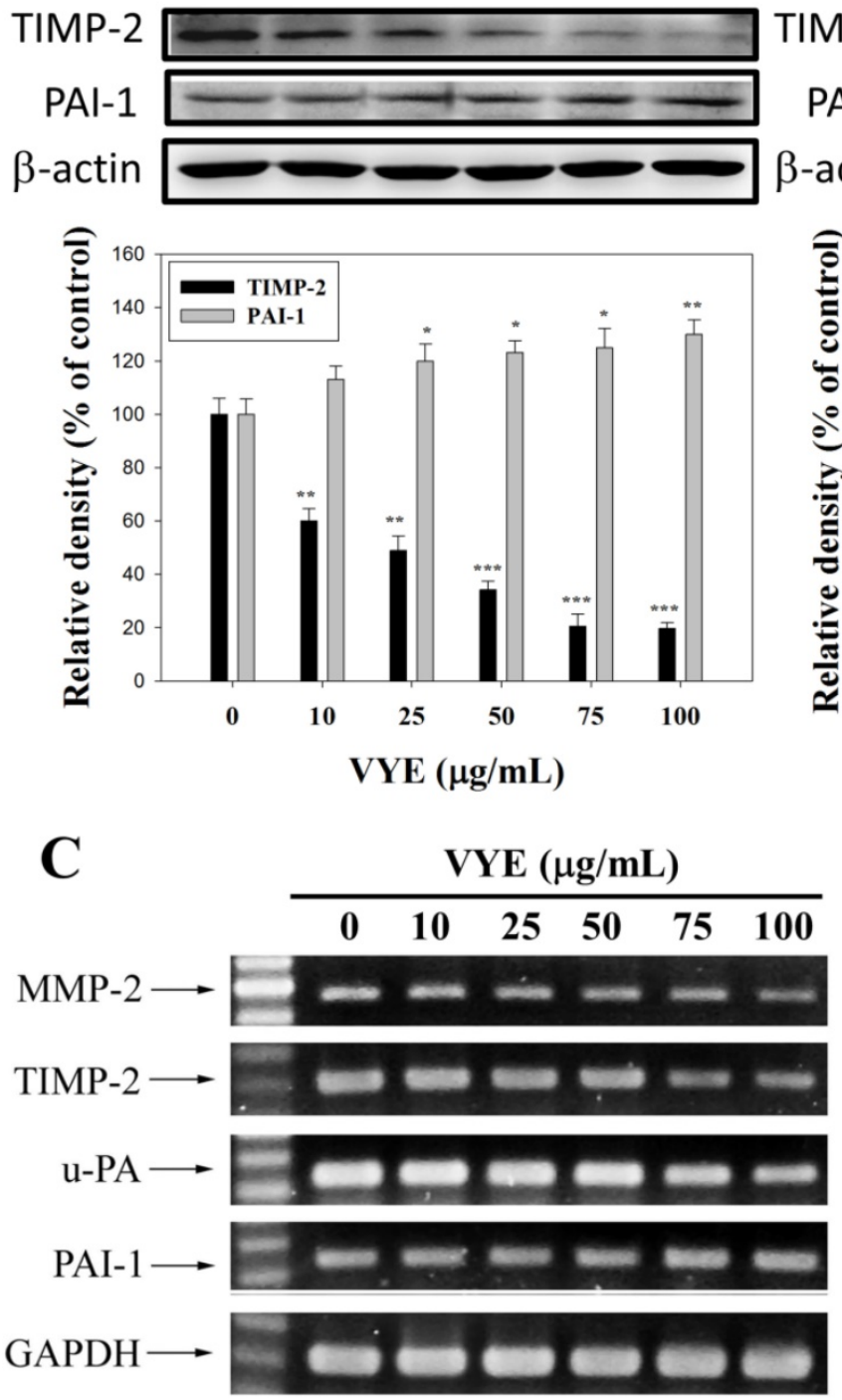

B
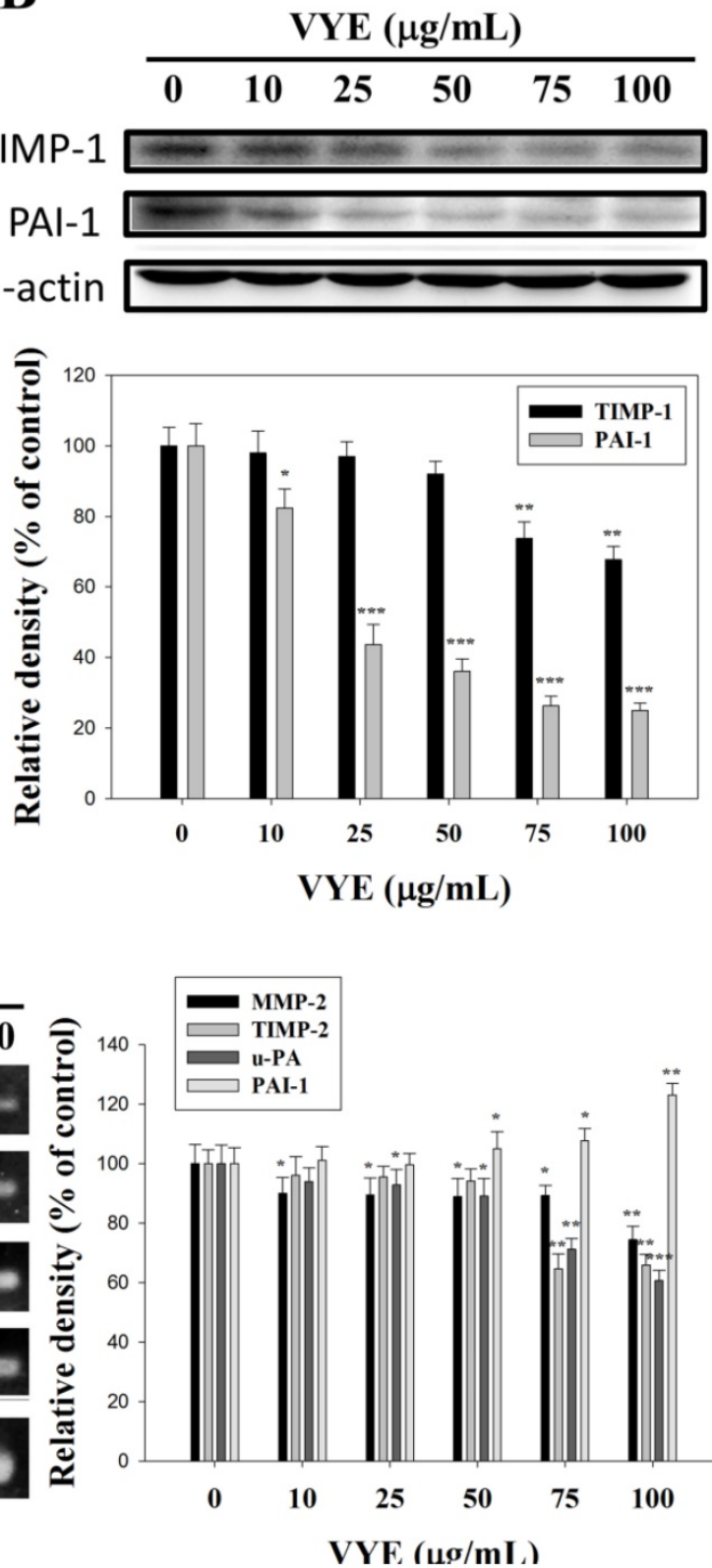

Figure 4. Effects of VYE on the protein and mRNA expression levels of TIMP and PAI-1 in the lung cancer cells. (A) Expression levels of TIMP-2 and PAl-1 after VYE treatments of A549 cells and (B) TIMP-1 and PAI-1 after VYE treatments of LLC cells were measured by Western blot analysis, with $\beta$-actin as the internal control. (C) For mRNA levels, A549 total RNAs were extracted and subjected to a semi-quantitative RT-PCR for MMP-2, u-PA, TIMP-2, and PAI-1 with GAPDH as the internal control. Similar results were obtained from three repeated and independent experiments using one-way ANOVA with post hoc Dunnett's test $(* P<0.05 ; * * P<0.01)$.

\section{Effects of VYE on MMP-2, u-PA, TIMP-2, and PAI-1 RNA levels in A549 cells}

The regulatory effects of VYE on the mRNA levels of proteases and their endogenous inhibitors were also validated by semi-quantitative RT-PCR analysis. With GAPDH as an internal control, the mRNA levels of MMP-2, u-PA, and TIMP-2 were significantly reduced, whereas those of PAI-1 were slightly increased in A549 cells (Figure 4C).

\section{VYE decrease NF-KB DNA binding activity}

The nuclear extract was analyzed by EMSA for NF- $\mathrm{BB}$ and AP-1 DNA binding activity to examine the association between the inhibitory effect of VYE on MMP-2 expression and the activities of NF- $\kappa B$ and AP-1. The result showed that the pre-treatment with VYE suppressed the NF- $\kappa B$ binding activity (Figure 5A) in A549 cells, whereas their AP-1 activity was not significantly different from that of the controls (Figure 5B). Subsequently, Western blot was performed to 
further confirm these results, and it was found that VYE suppressed the nuclear levels of NF- $\kappa B$ with $\mathrm{C} 23$ being the internal control in A549 cells (Figure 5C). As we have shown that a treatment of VYE to A549 cells inhibited the cell invasion and activities of MMP-2 and $\mathrm{u}-\mathrm{PA}$, the underlying mechanisms were further investigated. As shown in Figure 5D, VYE significantly inhibited the expression of p-p38, whereas it has no significant effect on Akt and ERK1/2 activity. Moreover, no significant change in the total amount of p38, ERK1/2, and Akt proteins was observed in A549 cells.

A
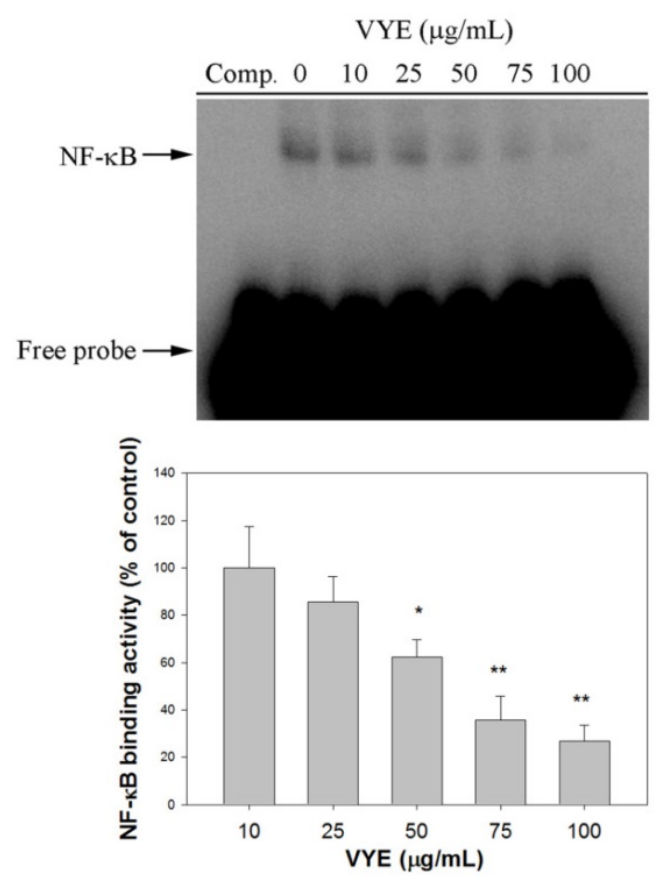

C

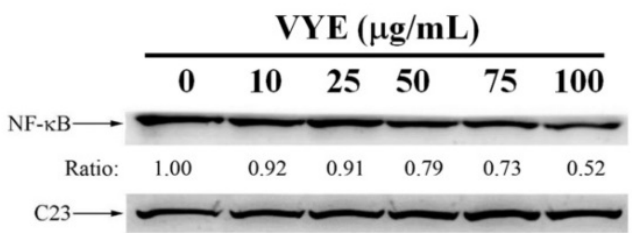

\section{Chromatographic patterns of VYE}

To evaluate the composition of VYE, we successively extracted the VYE with $50 \%$ ethanol. Chromatographic patterns from HPLC analysis of VYE showed peaks corresponding to the retention times. Absorbance was monitored at $254 \mathrm{~nm}$ (Figure 6).

In summary, these findings suggested that VYE can transcriptionally regulate MMP-2 and u-PA expression via the down-regulation of NF- $\mathrm{KB}$ pathway and consequently inhibit lung cancer cell metastasis (Figure 7).

\section{B}

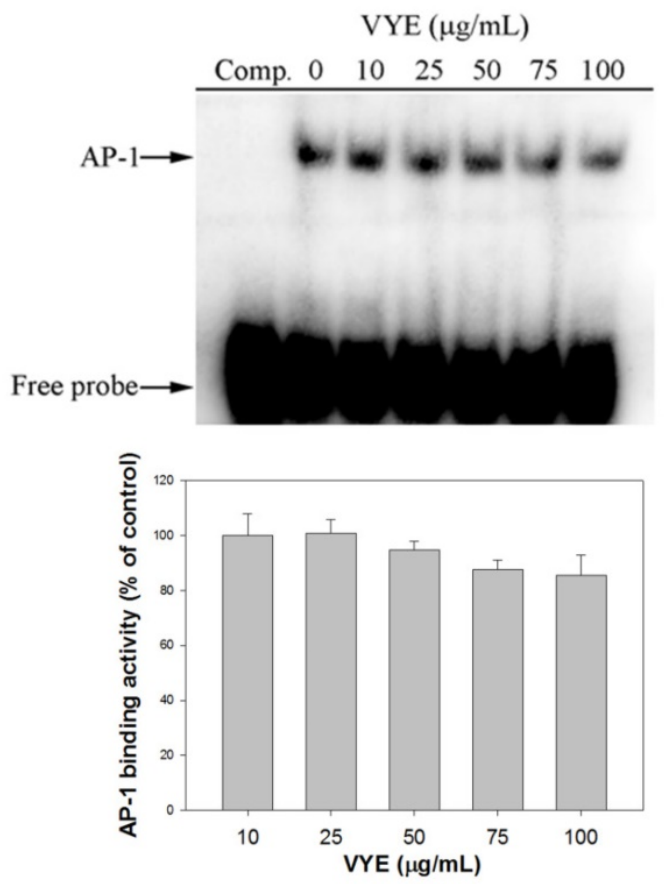

D

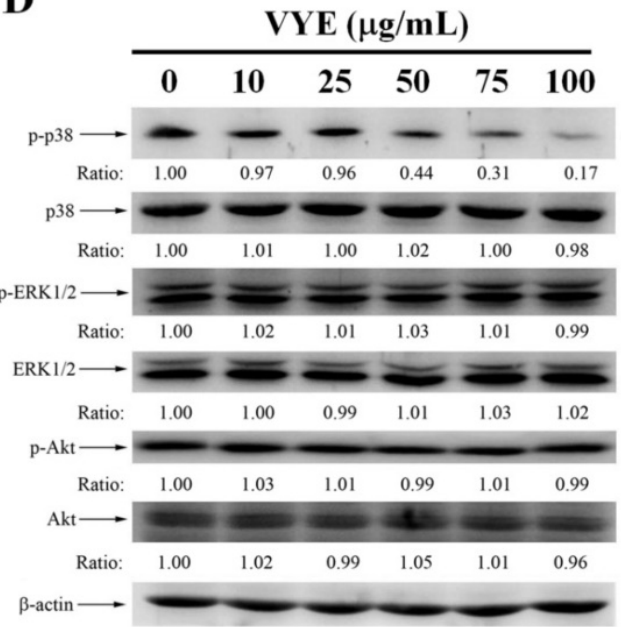

Figure 5. Inhibitory effects of VYE on DNA binding activity of NF-KB in A549 cells. A549 nuclear extracts were analyzed for DNA binding activity of (A) NF- $\kappa$ B and (B) AP-1 using biotin-labeled NF- $\kappa B$ and AP-1-specific oligonucleotide in EMSA. (C) Nuclear extracts were subjected to SDS-PAGE followed by Western blotting with anti-NF- $K B$ and C23 antibodies. (D) Cell lysates were subjected to SDS-PAGE followed by Western blotting with anti-p38, anti-phosho-p38, anti-ERK1/2, anti-phosho-ERK1/2, anti-Akt, and anti-phosho-Akt antibodies. Similar results were obtained from three repeated and separate experiments. 


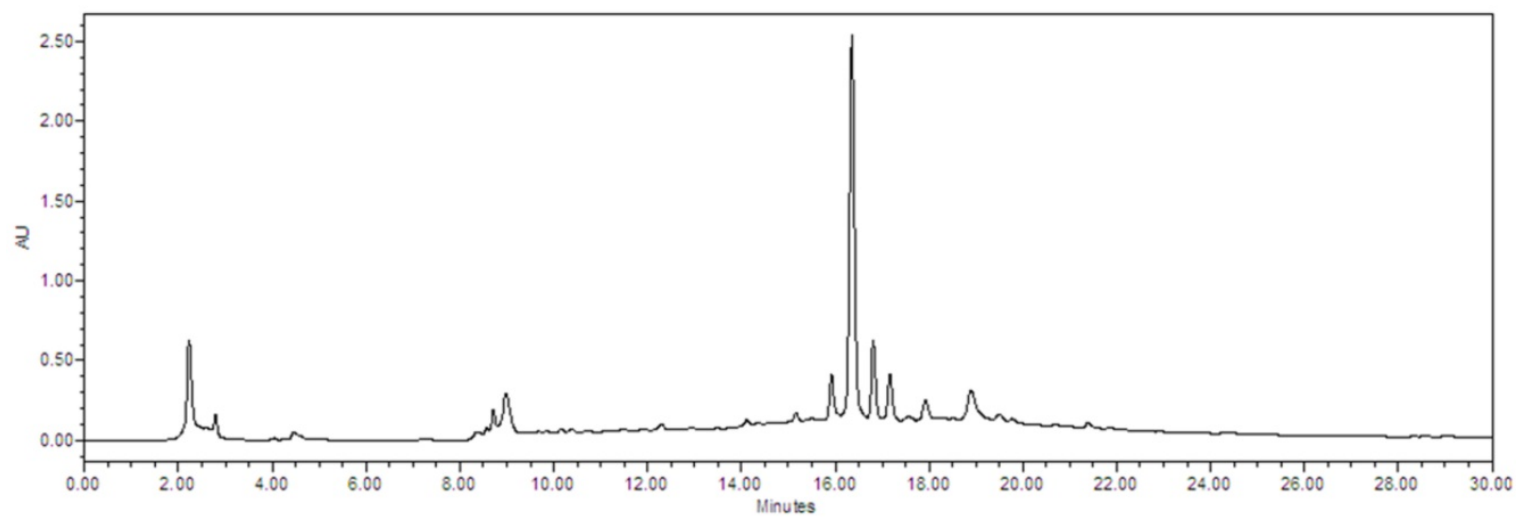

Figure 6. The chemical profile of VYE was analyzed by HPLC-mass spectrometry. Chromatographic patterns from HPLC analysis of VYE extracts showed peaks corresponding to the retention times ( $\mathrm{min})$. Absorbance was monitored at $254 \mathrm{~nm}$.

\section{Discussion}

Metastasis is the spread of tumor cells from the primary site to other organs of the body; this process includes reducing the intercellular interaction, increasing the adhesion of cell-matrix, damaging the ECM components, and increasing the invasion and migration of cancer cells [27]. Metastasis is the major cause of death in patients with lung cancer and is an intricate and multiple process that may lead to poor prognosis and complicated clinical management for cancer patients [7]. Various treatments have targeted the prevention of cancer metastasis. This study investigated the anti-cancer effects of VYE on lung cancer cells. We provided substantial evidence that VYE suppressed the migratory and invasiveness potential of cancer cells in A549 and LLC cell lines (Figure 2). The breakdown of the ECM of the basement membrane for invasion and metastasis by cancer cells was mediated by expressing high levels of proteases, such as MMPs and u-Pas, which degrade

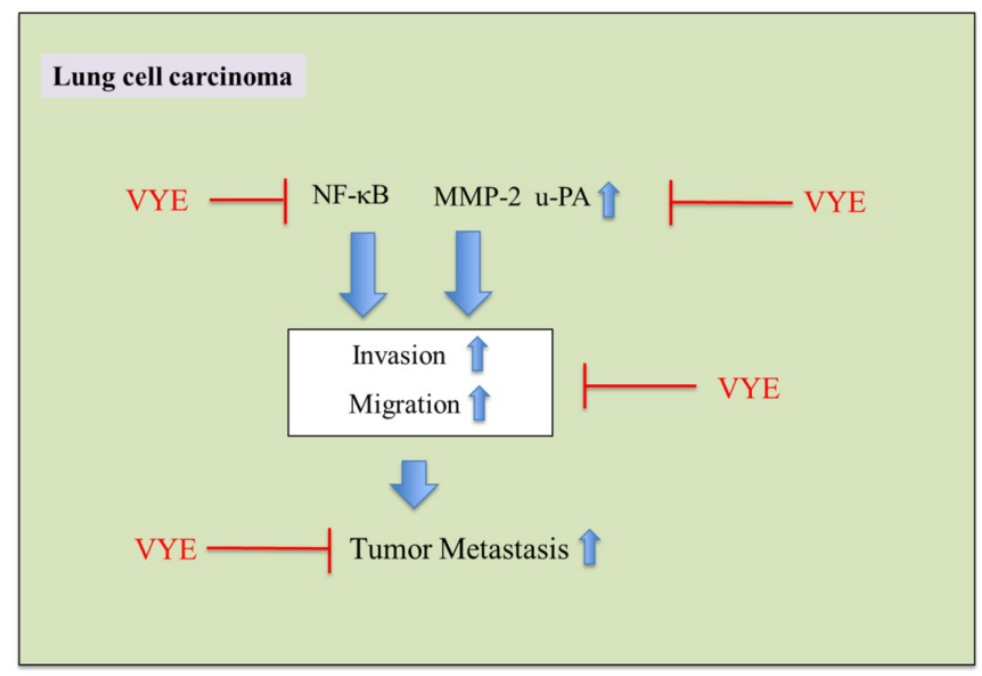

Figure 7. Proposed molecular targets in anti-invasiveness efficacy of VYE in lung cancer cells. the ECM of tissues and facilitate cancer invasion and metastasis [28]. The activities of MMPs and u-PA are prone to the inhibition of endogenous TIMPs and PAIs, which are specific inhibitors of MMPs and $\mathrm{u}-\mathrm{PA}$; the imbalance between proteases and their endogenous inhibitors may contribute to the degradation or deposition of ECM [29,30]. TIMPs and PAI have been shown to reduce tumor growth and metastatic potential in cell and animal model systems [31]. The results of the current study show that VYE reduced the levels of enzymatic activities and the protein expression of MMP-2, MMP-9, and u-PA, which were secreted into the serum-free conditioned medium by A549 and LLC cells (Figures 3 and 4). The protein expression levels of TIMP-2 and TIMP-1 were gradually reduced with the increasing concentration of VYE in A549 and LLC cells, respectively. PAI-1 protein expression levels were gradually increased in A549 cells but gradually suppressed in LLC cells with the increasing concentration of VYE (Figure 4). This suppression of MMP or u-PA expression was correlated with the results of RT-PCR analysis, revealing that VYE dose-dependently reduced the mRNA levels of MMPs and u-PA (Figure 4).

Recent studies have shown that the activation of NF- $\mathrm{kB}$ and $\mathrm{AP}-1$ is associated with angiogenesis, inflammation, and tumor metastasis [3, 32]; the down-regulation of any of these transcription factors is potentially an effective strategy to block cancer invasion and metastasis. The activities of AP-1 or NF- $\kappa B$ may inhibit MMP-2 or u-PA synthesis and thus block the factors that bind to these regulatory elements. Hence, this method is suitable to suppress the synthesis of MMPs or u-PA. Therefore, we tested the effect of VYE in NF- $\mathrm{KB}$ and AP-1 activities. VYE effectively suppressed the 
binding of NF- $\kappa B$ to DNA in their DNA-binding domains (Figure 5). Based on these observations, the inhibition of NF- $\mathrm{KB}$ activities may inhibit MMP-2 or u-PA expression levels and potentially reduce tumor initiation, promotion, and metastasis.

Chemotherapy drugs kill cancer cells but can also damage healthy cells and exhibit systemic toxicity and side effects. Therefore, reducing the systemic toxicity caused by chemotherapeutic agents is a major challenge in maximizing the beneficial outcome of cancer treatment. Phytotherapeutic agents with considerable anti-tumor effects and low toxicity to normal tissues have been suggested as possible alternatives due to their capability to improve the efficacy of anti-cancer drugs [33]. In this study, VYE exerted anti-tumor effects on highly metastatic lung carcinoma A549 and LLC cells but did not show any significant cytotoxicity on non-malignant human fetal lung fibroblast MRC-5. Therefore, VYE can be combined with doxorubicin or cisplatin to form an adjuvant for the chemotherapy of patients with advanced lung cancer.

Earlier reports have indicated that $V$. yedoensis focuses on the effects of anti-inflammatory and antibacterial activities, but its effect on the migration and invasion of tumor cells has never been mentioned. In this study, we first demonstrated that VYE significantly affected the migration and invasion of highly metastatic A549 and LLC lung carcinoma cells. $V$. yedoensis potentially inhibited the invasion, migration, and proteinase activities of lung cancer cells. Therefore, this herb can be used as a valuable tool in the combination therapy of metastatic lung carcinoma and the prevention of lung cancer metastases.

\section{Acknowledgements}

This study was financially supported by clinical research grants from the Kaohsiung Armed Forces General Hospital, Kaohsiung, Taiwan [106-09] and the Ministry of Science and Technology, Taiwan [106-2320-B-040-020-MY3 and 106-2320-B-040 -016].

\section{Competing Interests}

The authors have declared that no competing interest exists.

\section{References}

[1] Rao JS. Molecular mechanisms of glioma invasiveness: the role of proteases. Nat Rev Cancer. 2003;3:489-501.

[2] Huang SF, Horng $\mathrm{CT}$, Hsieh $\mathrm{YS}$, Hsieh $\mathrm{YH}$, Chu SC, Chen PN. Epicatechin-3-gallate reverses TGF-beta1-induced epithelial-to-mesenchymal transition and inhibits cell invasion and protease activities in human lung cancer cells. Food Chem Toxicol. 2016;94:1-10.

[3] Zhao M, Gao Y, Wang L, Liu S, Han B, Ma L, Ling Y, Mao S, Wang X. Overexpression of integrin-linked kinase promotes lung cancer cell migration and invasion via NF-kappaB-mediated upregulation of matrix metalloproteinase-9. Int J Med Sci. 2013;10:995-1002.
[4] Roomi MW, Kalinovsky T, Rath M, Niedzwiecki A. Modulation of u-PA, MMPs and their inhibitors by a novel nutrient mixture in human female cancer cell lines. Oncol Rep. 2012;28:768-776.

[5] Tee YT, Wang PH, Tsai HT, Lin LY, Lin HT, Yang SF, Hsieh YH, Ying TH. Genetic polymorphism of urokinase-type plasminogen activator is interacting with plasminogen activator inhibitor-1 to raise risk of cervical neoplasia. J Surg Oncol. 2012;106:204-208.

[6] Edwards BK, Brown ML, Wingo PA, Howe HL, Ward E, Ries LA, Schrag D, Jamison PM, Jemal A, Wu XC, Friedman C, Harlan L, Warren J, Anderson RN, Pickle LW. Annual report to the nation on the status of cancer, 1975-2002, featuring population-based trends in cancer treatment. J Natl Cancer Inst. 2005;97:1407-1427.

[7] Tang JM, He QY, Guo RX, Chang XJ. Phosphorylated Akt overexpression and loss of PTEN expression in non-small cell lung cancer confers poor prognosis. Lung Cancer. 2006;51:181-191.

[8] Suh SS, Yang EJ, Lee SG, Youn UJ, Han SJ, Kim IC, Kim S. Bioactivities of ethanol extract from the Antarctic freshwater microalga, Chloromonas sp. Int J Med Sci. 2017;14:560-569.

[9] Liu CH, Tang WC, Sia P, Huang CC, Yang PM, Wu MH, Lai IL, Lee KH. Berberine inhibits the metastatic ability of prostate cancer cells by suppressing epithelial-to-mesenchymal transition (EMT)-associated genes with predictive and prognostic relevance. Int J Med Sci. 2015;12:63-71.

[10] Zhou HY, Hong JL, Shu P, Ni YJ, Qin MJ. A new dicoumarin and anticoagulant activity from Viola yedoensis Makino. Fitoterapia. 2009;80:283-285.

[11] Jeong YH, Oh YC, Cho WK, Shin H, Lee KY, Ma JY. Anti-inflammatory effects of Viola yedoensis and the application of cell extraction methods for investigating bioactive constituents in macrophages. BMC Complement Altern Med. 2016;16:180.

[12] Muluye RA, Bian Y, Alemu PN. Anti-inflammatory and Antimicrobial Effects of Heat-Clearing Chinese Herbs: A Current Review. J Tradit Complement Med. 2014;4:93-98.

[13] Cao J, Yin C, Qin Y, Cheng Z, Chen D. Approach to the study of flavone di-C-glycosides by high performance liquid chromatography-tandem ion trap mass spectrometry and its application to characterization of flavonoid composition in Viola yedoensis. J Mass Spectrom. 2014;49:1010-1024.

[14] Wang CK, Colgrave ML, Gustafson KR, Ireland DC, Goransson U, Craik DJ. Anti-HIV cyclotides from the Chinese medicinal herb Viola yedoensis. J Nat Prod. 2008;71:47-52.

[15] Zeng HR, Wang B, Zhao Z, Zhang Q, Liang MY, Yao YQ, Bian K, Zhang WR. Effects of Viola yedoensis Makino anti-itching compound on degranulation and cytokine generation in RBL-2H3 mast cells. J Ethnopharmacol. 2016;189:132-138.

[16] Lin CY, Chen PN, Hsieh YS, Chu SC. Koelreuteria formosana extract impedes in vitro human LDL and prevents oxidised LDL-induced apoptosis in human umbilical vein endothelial cells. Food Chem. 2014;146:299-307.

[17] Lu KH, Chen PN, Lue KH, Lai MT, Lin MS, Hsieh YS, Chu SC. 2'-hydroxyflavanone induces apoptosis of human osteosarcoma 143 B cells by activating the extrinsic TRAIL- and intrinsic mitochondria-mediated pathways. Nutr Cancer. 2014;66:625-635.

[18] Hsieh YS, Chu SC, Yang SF, Chen PN, Liu YC, Lu KH. Silibinin suppresses human osteosarcoma MG-63 cell invasion by inhibiting the ERK-dependent c-Jun/ AP-1 induction of MMP-2. Carcinogenesis. 2007;28:977-987.

[19] Lu KH, Yang HW, Su CW, Lue KH, Yang SF, Hsieh YS. Phyllanthus urinaria suppresses human osteosarcoma cell invasion and migration by transcriptionally inhibiting u-PA via ERK and Akt signaling pathways. Food Chem Toxicol. 2013;52:193-199.

[20] Lin CY, Hsieh YH, Yang SF, Chu SC, Chen PN, Hsieh YS. Cinnamomum cassia extracts reverses TGF-beta1-induced epithelial-mesenchymal transition in human lung adenocarcinoma cells and suppresses tumor growth in vivo. Environ Toxicol. 2017;32:1878-1887.

[21] Lu KH, Chen PN, Hsieh YH, Lin CY, Cheng FY, Chiu PC, Chu SC, Hsieh YS. 3-Hydroxyflavone inhibits human osteosarcoma U2OS and 143B cells metastasis by affecting EMT and repressing u-PA/MMP-2 via FAK-Src to MEK/ERK and RhoA/MLC2 pathways and reduces 143B tumor growth in vivo. Food Chem Toxicol. 2016;97:177-186.

[22] Yang JS, Lin CW, Hsieh YS, Cheng HL, Lue KH, Yang SF, Lu KH. Selaginella tamariscina (Beauv.) possesses antimetastatic effects on human osteosarcoma cells by decreasing MMP-2 and MMP-9 secretions via p38 and Akt signaling pathways. Food Chem Toxicol. 2013;59:801-807.

[23] Lin CH, Hsiao YM, Ou CC, Lin YW, Chiu YL, Lue KH, Chang JG, Ko JL. GMI, a Ganoderma immunomodulatory protein, down-regulates tumor necrosis factor alpha-induced expression of matrix metalloproteinase 9 via NF-kappaB pathway in human alveolar epithelial A549 cells. J Agric Food Chem. 2010;58:12014-12021.

[24] Chen PN, Yang SF, Yu CC, Lin CY, Huang SH, Chu SC, Hsieh YS. Duchesnea indica extract suppresses the migration of human lung adenocarcinoma cells by inhibiting epithelial-mesenchymal transition. Environ Toxicol. 2017;32:2053-2063.

[25] Hsieh YS, Chu SC, Hsu LS, Chen KS, Lai MT, Yeh CH, Chen PN. Rubus idaeus L. reverses epithelial-to-mesenchymal transition and suppresses cell invasion and protease activities by targeting ERK1/2 and FAK pathways in human lung cancer cells. Food Chem Toxicol. 2013;62:908-918.

[26] Chu SC, Yu CC, Hsu LS, Chen KS, Su MY, Chen PN. Berberine reverses epithelial-to-mesenchymal transition and inhibits metastasis and 
tumor-induced angiogenesis in human cervical cancer cells. Mol Pharmacol. 2014;86:609-623.

[27] Valastyan S, Weinberg RA. Tumor metastasis: molecular insights and evolving paradigms. Cell. 2011;147:275-292.

[28] Pulyaeva H, Bueno J, Polette M, Birembaut P, Sato H, Seiki M, Thompson EW. MT1-MMP correlates with MMP-2 activation potential seen after epithelial to mesenchymal transition in human breast carcinoma cells. Clin Exp Metastasis. 1997;15:111-120.

[29] McMahon BJ, Kwaan HC. Components of the Plasminogen-Plasmin System as Biologic Markers for Cancer. Adv Exp Med Biol. 2015;867:145-156.

[30] Merchant N, Nagaraju GP, Rajitha B, Lammata S, Jella KK, Buchwald ZS, Lakka SS, Ali AN. Matrix metalloproteinases: their functional role in lung cancer. Carcinogenesis. 2017;38:766-780.

[31] Whitley BR, Palmieri D, Twerdi CD, Church FC. Expression of active plasminogen activator inhibitor-1 reduces cell migration and invasion in breast and gynecological cancer cells. Exp Cell Res. 2004;296:151-162.

[32] Lee HY, Crawley S, Hokari R, Kwon S, Kim YS. Bile acid regulates MUC2 transcription in colon cancer cells via positive EGFR/PKC/Ras/ERK/CREB, PI3K/Akt/IkappaB/NF-kappaB and p38/MSK1/CREB pathways and negative JNK/c-Jun/AP-1 pathway. Int J Oncol. 2010;36:941-953.

[33] Chen WT, Yang TS, Chen HC, Chen HH, Chiang HC, Lin TC, Yeh CH, Ke TW, Chen JS, Hsiao KH, Kuo ML. Effectiveness of a novel herbal agent MB-6 as a potential adjunct to 5-fluoracil-based chemotherapy in colorectal cancer. Nutr Res. 2014;34:585-594. 